\title{
DIREITO DAS CULTURAS E IDENTIDADE: A PRÁTICA DA VAQUEJADA COMO DIREITO CULTURAL SEGUNDO VOTO DO MINISTRO GILMAR MENDES NO JULGAMENTO DA ADI 4.983
}

\author{
CULTURAL RIGHTS AND IDENTITY: THE PRACTICE OF VAQUEJADA \\ AS A CULTURAL RIGHT ACCORDING TO THE MINISTER GILMAR \\ MENDES VOTE IN THE ADI 4.983 JUDGMENT
}

Gustavo Polis ${ }^{\mathrm{I}}$

Jacopo Paffarini ${ }^{\mathrm{II}}$

\begin{abstract}
${ }^{I}$ Faculdade Meridional, Passo Fundo, RS, Resumo: O presente trabalho possui como temática a Brasil. Mestrando em Direito. E-mail: polis.g@outlook.com

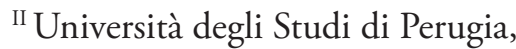
Perugia, Itálica e Faculdade Meridional,

Passo Fundo, RS, Brasil. Doutor em Direito.

formação da identidade cultural e a proteçâao jurídica aos direitos das culturas. O problema de pesquisa que orienta a produção do trabalho é: A prática da vaquejada foi colocada como objeto de proteção constitucional por ser considerada um direito cultural no voto do Ministro Gilmar Mendes no julgamento da ADI 4.983 pelo Supremo Tribunal Federal? O objetivo do trabalho é demonstrar como a prática da vaquejada foi retratada como um direito de caráter cultural na argumentaçáo utilizada pelo Ministro Gilmar Mendes em seu voto no julgamento da ADI 4.983. Adota-se a hipótese de que a prática da vaquejada foi considerada no voto do Ministro Gilmar Mendes como sendo uma manifestação cultural e desportiva do Estado do Ceará e, portanto, constitucionalmente assegurada como direito cultural. O método de pesquisa é o hipotético dedutivo, baseado em pesquisas, análises bibliográficas e jurisprudenciais.
\end{abstract}

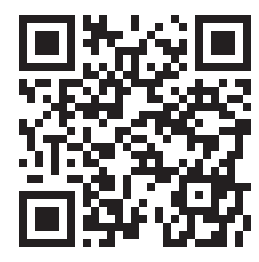

DOI: http://dx.doi.org/10.20912/rdc.v15i37.224

Recebido em: 04.02.2020

Aceito em: 11.08.2020
Palavras-chave: Identidade Cultural; Direito das Culturas; ADI 4.983.

Abstract: The present work has as its theme the formation of cultural identity and the legal protection of the rights of cultures. The research problem that guides the production of the work is: Was the practice of vaquejada seen as an object of constitutional protection because it is considered a cultural right in the vote of Minister Gilmar Mendes in the judgment of ADI 4.983 by the Federal Supreme Court? The purpose of the paper is to demonstrate how the practice of the vaquejada was portrayed as a cultural right in the argumentation used by Minister Gilmar Mendes in his vote in the trial of ADI 4.983. The hypothesis is that the practice of vaquejada was considered in the vote of Minister Gilmar Mendes as being a cultural and sports event in the State of Ceará and, therefore, 
constitutionally guaranteed as a cultural right. The research method is the hypothetical deductive, based on research, bibliographical and jurisprudential analysis.

Keywords: Cultural identity; Cultural rights; ADI 4.983.

\section{Introdução}

A formação da identidade cultural dos indivíduos é há muito assunto de fundamental importância para todas as ciências sociais e humanas. A construção identitária dos grupos sociais está diretamente conectada com as açóes, práticas e, inclusive, problemas sociais que assolam todo e qualquer agrupamento social. Dito isso, é importante para a análise de toda e qualquer sociedade o entendimento do processo de desenvolvimento da identidade cultural daquele determinado local, motivo pelo qual esta matéria também é objeto de estudo e reflexão do Direito, que a absorve com o desiderato de ser mais efetivo quando inseridos nos diferentes grupos sociais.

O constitucionalismo, não podendo ser de forma diferente, a partir do início do século XX, iniciou um processo de inserção dos direitos culturais no rol de direitos dignos de proteção das cartas constitucionais, ainda que de forma superficial nessa primeira fase. Avançando nessa temática, a partir da segunda metade do mesmo século, observou-se um maior detalhamento dos direitos culturais dentro das constituiçóes e, principalmente, os reconhecendo como direitos de caráter fundamental. Esse é o caso da Constituição Federal brasileira de 1988, que em seu artigo 215 coloca os direitos de matriz cultural em pé de igualdade com os demais direitos fundamentais.

A cultura em si é algo móvel, que não fica inerte ao longo do tempo e, sendo assim, a partir da positivaçáo desses fenômenos sociais, cedo ou tarde acabam por chegar ao Poder Judiciário. Recentemente, um dos casos de maior destaque acadêmico e social acerca da judicialização envolvendo direitos culturais no Brasil foi o julgamento da Açáo Direta de Inconstitucionalidade n. 4.983 pelo Supremo Tribunal Federal, que teve como objeto de debate a declaração de inconstitucionalidade de um dispositivo legal do Estado do Ceará que regulamentou a prática da vaquejada.

Assim, o presente trabalho possui como temática a formaçáo da identidade cultural e a proteção jurídica aos direitos das culturas. O problema de pesquisa do trabalho é: A prática da vaquejada foi colocada como objeto de proteçấo constitucional por ser considerada um direito cultural no voto do Ministro Gilmar Mendes no julgamento da ADI 4.983 pelo Supremo Tribunal Federal? O objetivo central é demonstrar como a prática da vaquejada foi retratada como um direito de caráter cultural na argumentaçáo utilizada pelo Ministro Gilmar Mendes em seu voto no julgamento da AD 4.983. Adotase a hipótese de que a prática da vaquejada foi considerada no voto do Ministro Gilmar 
Mendes como sendo uma manifestação cultural e desportiva do Estado do Ceará e, portanto, constitucionalmente assegurada como direito cultural. $\mathrm{O}$ método de pesquisa é o hipotético dedutivo, baseado em pesquisas, análises bibliográficas e jurisprudenciais.

Para que os objetivos do trabalho sejam adimplidos, o texto subdivide-se em 3 sessóes, quais sejam: (1) No primeiro capítulo, serão delineados os principais aspectos acerca da identidade cultural, pormenorizando seu processo de construçáo e a sua importância para a realidade social; (2) O segundo capítulo tratará de dissecar o crescente processo de proteção aos direitos culturais e, em especial, a proteção que esses direitos gozam dentro do sistema jurídico brasileiro; e (3) No terceiro e último capítulo, será realizada uma análise do voto do Ministro Gilmar Mendes no julgamento da ADI 4.983, com o intuito de compreender sua argumentaçáo a partir da ideia de direitos culturais para fundamentar sua decisão sobre a possibilidade de regulamentação da vaquejada.

\section{Principais aspectos acerca da identidade cultural}

A identidade cultural pode ser vista a partir de diferentes aspectos. A identidade pode ser vista tanto quanto um atributo de personalidade, quanto como um direito de caráter difuso, que acompanha determinado grupo socialmente relevante. $\mathrm{O}$ direito à identidade cultural pode e deve ser considerado como um direito fundamental, assim, possuindo um caráter de instrumentalidade e, também, de indivisibilidade ${ }^{1}$.

É relevante notar, antes das demais consideraçóes, que no âmbito das pesquisas científicas envolvendo, direta ou indiretamente, aspectos relacionados com a identidade cultural em conexão com o Direito, é necessário ter um olhar especial para algumas questóes. A identidade cultural deve ser encarada como um fenômeno social e antropológico, que existe na realidade social independentemente de seu reconhecimento por parte dos sistemas jurídicos ${ }^{2}$ por isso é fundamental buscar compreender a identidade cultural em conexão com vários aspectos, tal qual a economia e as relaçóes de poder onde estes agrupamentos estão inseridos.

Em essência, é possível entender a ideia de identidade como a fonte primeira de significado a da experiência de um povo. É um processo de construção de significado com base em um atributo cultural ou até mais em um grande conjunto de atributos culturais que passam a se relacionar entre si e, dentre estes, alguns prevalecem sobre outras fontes de significados ${ }^{3}$.

1 SOUZA, Pedro Bastos de. Identidade e Diversidade Cultural como Direitos Fundamentais: Relação de instrumentalidade e perspectivas no contexto internacional. Revista Videre, Dourados, v. 8, n. 15, p.147-167, jun. 2016, p. 148.

2 Idem.

3 CASTELLS, Manuel. O poder da identidade. A era da informação: economia, sociedade e cultura. Volume II. Tradução: Klauss Brandini Gerhardt. São Paulo: Paz e Terra, 2001, p. 22. 
Manuel Castells aponta para a fundamental distinção entre dois conceitos que são constantemente desempenhados pelos indivíduos na sociedade: Identidade e papéis. De um lado os papéis (operário, pai, mãe) são estabelecidos por normas das instituiçóes e organizaçóes sociais, já as identidades, de outra banda, são criadas pelos atores sociais e são constituídas por meio de movimentos de individualização. Em determinados casos as identidades podem ser formadas por instituiçôes socialmente dominantes, pelo fato de os indivíduos internalizam esse desejo de construir sua identidade a partir dessas instituiçóes ${ }^{4}$.

Partindo dessas premissas, é de se concluir que todas as identidades são construídas, a questão que permanece em aberto é questionar como, por que, por quem e a partir de que essa construção identitária se dá. A construção da identidade se desenvolve a partir de elementos que são fornecidos pelo conteúdo da Antropologia, História, Geografia e Biologia, assim como pelas instituiçóes, pela memória coletiva, pela religiáo e crenças individuais, dentre demais fatores, os indivíduos, por sua vez, processam e reorganizam esses conteúdos de acordo com suas respectivas vidas e culturas 5 .

A identidade de um povo ou de uma cultura como um todo é resultado direto de um amálgama de costumes, comportamentos, valores e dos chamados elementos socioculturais, como é o caso da religião e da língua local. Em contrapartida, o conceito de identidade nacional pode incidir em erro quanto a identificaçáo da identidade cultural de um determinado povo, na medida em que se reconhece que toda identidade é formada sobre a diferença, assim, na busca pela identidade cultural é essencial o respeito pelas diferenças existentes na comunidade 6 .

A discussão acerca da diferença se revela importante para o debate sobre a sociedade multicultural. As diferenças são fruto de um processo humano e social e, do mesmo modo, de um longo processo histórico e constitui, simultaneamente, um resultado e uma condição transitória. É resultado ao passo em que se considera o passado e privilegia-se o processo que resultou na diferença e é uma condição transitória quando se privilegia a continuidade da dinâmica já existente e, após, se configurará novamente ${ }^{7}$.

A identificação - aproximação - com o outro semelhante, através de diferentes situaçóes, é deveras importante para a construção da vida em sociedade. Por outro lado, a descrição e conceituação satisfatória da identidade cultural não tem conseguido angariar amplo espaço nas produçóes acadêmicas das ciências socais. Isso decorre pelo fato de que, com certa frequência, dois tipos de reducionismo existem na literatura analítica da sociedade e da econômica no que concerne a identidade cultural, quais sejam:1)

4 Ibidem, p. 23.

5 SPAREMBERGER, Raquel Fabiana Lopes; COLAÇO, Thais Luzia. Direito e identidade das comunidades tradicionais: Do direito do autor ao direito à cultura. Liinc em Revista, Rio de Janeiro, v. 7, n. 2, p.681-700, jul. 2011, p. 684 .

6 Idem.

7 SEMPRINI, Andrea. Multiculturalismo. Tradução: Laureano Pelegrin. Bauru, SP: Edusc, 1999, p. 58. 
desconsideração da identidade cultural; e, em sua contraposição, 2) a filiação singular ou única ${ }^{8}$.

A primeira corrente (1) diz respeito àqueles que ignoram ou negligenciam por completo a influência dos sentimentos de identidade com os demais integrantes do grupo, o que valorizam e como se comportam como uma coletividade. Este tipo de raciocínio acerca da identidade cultural está presente em um número relevante de teorias econômicas quando, por exemplo, acreditam que na escolha de seu futuro, objetivos e respectivos desígnios, as pessoas ignoram totalmente seus sentimentos de identidade para com seus semelhantes e comunidades, apenas olhando para os seus próprios desejos 9

A seu turno, a segunda corrente (2) corresponde a exatamente o contrário pelo trazido pela primeira corrente, na medida em que considera que todos os indivíduos, acima de tudo, estão ligados, para quaisquer fins práticos, a um específico grupo social. Sinala-se que a corrente da filiação singular ou única frequentemente atrai os pensadores comunitários e os teóricos da política cultural que desenvolvem suas teorias a partir da divisão da população em categorias civilizacionais ${ }^{10}$.

Embora ambas as linhas de pensamento acima descritas serem, de fato, muito difundidas nos diferentes campos do conhecimento, fica evidente, a partir do reconhecimento da importância da identidade cultural na construção social, que tanto a ideia da desconsideraçáo da identidade quanto da filiação singular ou única, são reducionistas. A hipótese de se desconsiderar por completo o papel que a formação da identidade culturas, bem como o seu funcionamento na realidade social, na formação da sociedade ou na análise dos seus diferentes aspectos é descabida. Igualmente, considerar que o grupo social ao qual se pertence é o único fator determinantes na escolha daquilo que os indivíduos acreditam que seja o correto, sem levar em conta demais aspectos, é demasiadamente simplista.

Essa tendência de buscar a classificação dos sujeitos de forma única para a realização de análises socais não é necessariamente nova. Demonstrativo disso é a diferenciação social entre agrupamentos políticos de pessoas entre trabalhadores, exaustivamente utilizado nos estudos socialistas ${ }^{11}$. Já é reconhecido que essa divisão era evidentemente equivocada, entretanto, vale ressaltar que o próprio Karl Marx submeteu essa identificaçáo única a uma rigorosa crítica em um de seus escritos, de 1875, chamado "Crítica ao Programa de Gotha.

8 SEN, Amartya. Identidade e Violência: A ilusão do destino. São Paulo: Luminuras, 2015. Tradução de: José Antônio Arantes, p. 38.

9 SEN, Amartya. Identidade e Violência: A ilusão do destino. São Paulo: Luminuras, 2015. Tradução de: José Antônio Arantes, p. 38.

10 Idem.

11 Ibidem, p. 42. 
Assim, tem-se que a cultura e a identidade correspondem a um processo acumulativo que se desvela a partir de toda a experiência histórica das geraçóes anteriores ${ }^{12}$. O desenrolar desse processo de desenvolvimento identitário limita ou estimula a ação criativa do indivíduo em tudo que o homem se propóe a fazer e aprender com os seus semelhantes e não decorre de imposições originadas fora da sua cultura.

A construção do conceito de cultura e de identidade envolve manifestaçóes das mais diferentes espécies, tal qual os bens de consumo, as normas que regem os diferentes grupos sociais, as ideias e as artes, as crenças e os costumes e, ainda, os aspectos humanos, materiais e espirituais ${ }^{13}$. Com isso, em consonância com o anteriormente exposto, é totalmente ilógico considerar aspectos singulares para definir ou conceituar a cultura e a identidade cultural de um povo, dado que a formação dessa identidade se dá por meio da associação de diversos aspectos presentes na realidade social.

Cada sujeito, em suas particularidades, possui uma identidade composta de diversas filiações e variantes, caracterizando um processo de identificaçóes historicamente apropriadas que conferem sentido ao grupo social. A identidade, nesse contexto, implica um sentimento de pertencimento a um determinado grupo étnico, cultural, religioso, a depender da percepção da diferença e da semelhança entre "ego" e o "alter", entre "nós" e os "outros"14.

A identidade reproduz e identifica o empenho que um grupo lança mão, durante um lapso de tempo considerável, na construção da memória. Com isso, pode-se concluir que a memória coletiva está na base da construção da identidade. A memória coletiva reforça o sentimento de pertença identitária e, de certa forma, garante a coesáo e continuidade histórica do grupo ${ }^{15}$. A memória pode ser entendida como processos sociais e históricos, de expressóes, de narrativas de acontecimentos marcantes, de coisas vividas, que legitimam, reforçam e reproduzem a identidade do grupo.

As identidades, que correspondem a diferenciaçóes em curso, emergem dos processos interativos que os indivíduos experimentam na sua realidade quotidiana, feita de trocas reais e simbólicas ${ }^{16}$. O passo-a-passo do processo de construção da identidade, seja individual ou social, não é um movimento estável e uniforme, é mutável, inventada e

12 SOUZA, Pedro Bastos de. Identidade e Diversidade Cultural como Direitos Fundamentais: Relação de instrumentalidade e perspectivas no contexto internacional. Revista Videre, Dourados, v. 8, n. 15, p.147-167, jun. 2016, p. 150.

13 SOUZA, Pedro Bastos de. Identidade e Diversidade Cultural como Direitos Fundamentais: Relaçáo de instrumentalidade e perspectivas no contexto internacional. Revista Videre, Dourados, v. 8, n. 15, p.147-167, jun. 2016, p. 150.

14 Ibidem, p. 151.

15 RODRIGUES, Donizete. Património cultural, Memória social e Identidade: uma abordagem antropológica. Revista Ubimuseum, n.01. Universidade da Beira Interior (POR), 2012. Disponível em http://www. ubimuseum.ubi.pt/. Acesso em dezembro de 2019, p. 5.

16 SANTOS, Boaventura de Sousa. Modernidade, identidade e a cultura de fronteira. Tempo Social. Rev. Social. USP, 5 (1-2): 31-52, 1994, p. 151. 
reinventada, transitória e, em determinadas situaçóes, provisória e subjetiva; a identidade, desse modo, vai se reconfigurando e reformando ao longo do tempo ${ }^{17}$.

Firmadas as premissas mais básicas dos conceitos de identidade cultural e cultura, no capítulo que se segue, o trabalho irá se ocupar, com maior e mais aprofundada ênfase, acerca da análise daquilo que se conhece como direito das culturas e o seu aparato de proteção presente na legislaçáo brasileira.

\section{Um panorama dos direitos das culturas e a sua proteção no sistema jurídico brasileiro}

O principal objetivo que move a ciência jurídica é a percepção e concretização da justiça no dia-a-dia do convívio social. Desde as relaçóes mais complexas até a as mais simples, as pessoas e os conceitos devem estar impregnados pelo valor do Direito. O processo de estruturaçáo ao qual as sociedades se submetem, dentre os mais variados campos que formam as suas preocupaçóes, colocam os direitos das culturas como um dos temas indicativos para a estruturação e organização das relaçóes humanas e sociais ${ }^{18}$.

Não restam dúvidas de que a formação cultural exerce uma profunda influência no pensamento e comportamento dos cidadáos, pelo fato de estar inserida e incutida no dia-a-dia da população de forma ininterrupta. De igual sorte, a qualidade de vida que os povos gozam também perpassa pela rede de influência que a cultura cria dentro das sociedades, bem como o sentimento de identidade e a percepçáo da filiaçáo a grupos dos quais as pessoas se veem como integrantes ${ }^{19}$.

Por outro lado, é importante pontuar que as identidades culturais são inegavelmente importantes, em que pese não sejam imunes a outros elementos de influência na sua configuração. Assomados a cultura, aspectos como gênero, classe social, etnia e profissão também possuem um papel complementar no reconhecimento cultural do cidadão. Igualmente, a cultura não é homogênea, na medida em que dentro de determinadas sociedades pode haver diferentes formaçóes culturais. A cultura, do mesmo modo, não é imóvel, ou seja, toda e qualquer cultura está submetida a um incessante processo de desenvolvimento, o que possui efeitos diretos no modo de vida das sociedades ${ }^{20}$.

É imprescindível que se reconheça a plurietnicidade e a pluriculturalidade que está presente na formação de grande parte dos países e suas respetivas regiôes e distritos

17 Ibidem, p. 152.

18 ZAMBAM, Neuro José; BOFF, Salete Oro. Direitos das Culturas e Tecnologia: Um debate que integra complexidade, tradição, diferenças e mudanças. Revista Direito e Justiça: Reflexóes sociojurídicas, Santo Ângelo, v. 24, p.73-84, maio 2015, p. 75.

19 SEN, Amartya. Identidade e Violência: A ilusão do destino. São Paulo: Luminuras, 2015. Tradução de: José Antônio Arantes, p. 124.

20 SEN, Amartya. Identidade e Violência: A ilusão do destino. São Paulo: Luminuras, 2015. Tradução de: José Antônio Arantes, p. 125. 
internos, o que confirma a já difundida teoria de que os Estados não possuem uma composição homogênea e, por isso, o reconhecimento e a tutela de todos os grupos, e suas particularidades, presentes em sua formação é fundamental para que a dignidade humana seja realmente protegida e respeitada ${ }^{21}$.

A cultura dos indivíduos, grupos, comunidades ou de sociedades representa a sua segurança afetiva. A identificação com a sua própria cultura mantém os grupos e os indivíduos que o compóem integrados a um todo maior e organizado de acordo com padróes e objetivos que comungam entre $\mathrm{si}^{22}$. Todavia, esse, como qualquer outro tipo de direito, não pode gerar, encorajar ou expandir concepçóes e práticas individualistas, sectárias ou que sejam contrárias ao estabelecimento de relações pautadas pela alteridade.

Desse modo, um ambiente multicultural deve ser orientado pela opção, capacidade e disposição de construir e estabelecer relações dialógicas, integradas e respeitosas para com os outros. Ao negar esta atitude dinâmica, que possui tanto o efeito pedagógico quanto didático, incide-se no risco de negar a legitimidade moral de determinada cultura. A superação de concepçóes isolacionistas e não dialógicas é condição primeira para que se crie o ambiente necessário para a efetiva formatação e a consequente proteção do direito das culturas ${ }^{23}$.

É imprescindível para uma sociedade democrática a preocupação com o direito das culturas e com seus infindáveis recursos e mecanismos de participação, representação, discussão, deliberação e decisão que complementam as demandas das culturas com as demais necessidades, proposições e grupos que habitam a sua órbita. Especialmente, o exercício desse direito depende diretamente do equilíbrio, das condiçóes e da dinâmica que faz caminho para o melhor exercício da cidadania ${ }^{24}$.

A estreita relação entre cultura, política e Direito existe já há muito tempo. Outrossim, a partir de uma análise histórica, esta relação demonstra ter se intensificado a partir da consolidaçáo do capitalismo e, consequentemente, da classe burguesa. $\mathrm{Na}$ porção ocidental do planeta, no período conhecido como modernidade, o Estado passa a se ocupar com a "questão das culturas" com maior ênfase ao longo do século XX, muito especialmente pela inclusão de previsões visando a proteção dos direitos relacionados a cultura nas constituiçóes emergentes durante esse período, como a mexicana de 1917, a constituição de Weimar de 1918 e aquelas cartas constitucionais escritas entre as duas guerras mundiais ${ }^{25}$.

21 SPAREMBERGER, Raquel Fabiana Lopes; COLAÇO, Thais Luzia. Direito e identidade das comunidades tradicionais: Do direito do autor ao direito à cultura. Liinc em Revista, Rio de Janeiro, v. 7, n. 2, p.681-700, jul. 2011, p. 682.

22 ZAMBAM, Neuro José; BOFF, Salete Oro. Direitos das Culturas e Tecnologia: Um debate que integra complexidade, tradição, diferenças e mudanças. Revista Direito e Justiça: Reflexóes sociojurídicas, Santo Ângelo, v. 24, p.73-84, maio 2015, p. 76.

23 Idem.

24 Ibidem, p. 77.

25 FERNANDES, Natalia Morato. A cultura como direito: reflexóes acerca da cidadania cultural. Semina: Ciências 
As constituiçóes escritas em especial na primeira metade do século XX abordavam a temática da cultura de uma forma vaga e sintética, assegurando, na maioria das vezes, o direito à livre manifestação do pensamento, os direitos autorais e de invenção como formas de direitos individuais ${ }^{26}$. Já as constituiçóes oriundas a partir da segunda metade do século XX em diante, passaram a alargar os horizontes de proteção à cultura, surgindo, então, a ideia dos direitos culturais como direitos fundamentais do homem, tendo como sua matriz o texto da Declaração Universal dos Direitos Humanos, de 1948, mais precisamente em seu artigo n. 27:

Artigo XXVI:

1. Todo ser humano tem o direito de participar livremente da vida cultural da comunidade, de fruir das artes e de participar do progresso científico e de seus benefícios.

2. Todo ser humano tem direito à proteção dos interesses morais e materiais decorrentes de qualquer produção científica literária ou artística da qual seja autor. ${ }^{27}$

Vale mencionar outros instrumentos internacionais que tentaram promover e conscientizar os países para que pudessem se movimentar no sentido de proteger os direitos culturais, os reconhecendo como direitos fundamentais, como o Pacto Internacional sobre Direitos Econômicos, Sociais e Culturais, de 1966 e, mais especificamente no contexto latino-americano, o Pacto de Sáo José da Costa Rica, também conhecido como Convenção Americana de Direitos Humanos, constituído em 1969.

Nessa toada, em especial a partir da década de 1970, acelerado pelo surgimento dos movimentos de globalização - cultural e econômica - os Estados Nacionais iniciaram um processo de reconfiguração interna para lidar com questóes impostas por esse novo cenário, na esfera da administração pública, econômica e social. Esse processo desencadeou alteraçóes profundas no trato das questóes envolvendo a cultura, ao passo em que se torna um nicho a ser economicamente explorável, bem como uma forma de difundir os padróes culturais das sociedades ${ }^{28}$.

A partir dessas novas roupagens institucionais, é importante salientar os movimentos dos países latino-americanos especialmente nas últimas três décadas. Fortaleceu-se de forma crescente a consciência e a mobilização social, dando origem a diversas transformaçóes nos continentes, em especial nos países andinos, como Bolívia e Equador, onde de forma legítima e democrática o poder político, juntamente do povo, promoveu uma série de arranjos no intuito de assentar um processo de descolonização ${ }^{29} \mathrm{a}$

Sociais e Humanas, [s.l.], v. 32, n. 2, p.171-182, 8 fev. 2013. Universidade Estadual de Londrina. http://dx.doi. org/10.5433/1679-0383.2011v32n2p171, p. 174.

26 Idem.

27 ORGANIZAÇÃO DAS NAÇÓES UNIDAS, ONU. Declaraçáo Universal dos Direitos Humanos, 1948.

28 FERNANDES, Natalia Morato. A cultura como direito: reflexôes acerca da cidadania cultural. Semina: Ciências Sociais e Humanas, [s.l.], v. 32, n. 2, p.171-182, 8 fev. 2013. Universidade Estadual de Londrina. http://dx.doi. org/10.5433/1679-0383.2011v32n2p171, p. 174.

29 WOLKMER, Antônio Carlos; FERRAZZO, Débora. Sistemas Plurais de Direito: Desde Práticas Sociais e 
partir da construção social baseado na valorização das culturas locais em detrimento dos expedientes eurocêntricos que marcaram as vidas coloniais desses países.

Promover a discussão sobre os contornos de processos desse cunho é de relevante importância, vez que viabiliza a identificação de novos paradigmas que são capazes de compreender e realizar o direito e, além disso, auxiliar na conscientização sobre os riscos da retomada de um processo de recolonização das conquistas democráticas ${ }^{30}$, em especial aquelas ligadas a promoção das culturas locais. Parte dessa postura, por exemplo, a crescente relevância do debate acerca dos contornos práticos e teóricos do chamado pluralismo jurídico.

No que toca a proteção dos direitos culturais no sistema jurídico brasileiro, não há um conjunto normativo específico sobre a matéria, mas vários fragmentos jurídicos esparsos pela Constituição Federal e legislações federais, estaduais e municipais. A Constituição Federal, n capítulo II, do Título II, cuida dos direitos sociais, que representam, consoante as melhores classificações, aqueles que expressam o dever do Estado em prover prestaçóes positivas para a efetivaçáo desses direitos. Nesse tópico que entram os direitos culturais, também como ligados à necessidade de uma postura afirmativa do Estado para sua eficácia ${ }^{31}$.

Com isso, fica evidenciado que cabe ao Estado brasileiro promover as condiçóes propícias para o surgimento e conservação de práticas culturais que expressem o patrimônio cultural do povo, o que marca e configura sua identidade. Pode-se afirmar que, no contexto brasileiro, os direitos culturais são aqueles ligados às artes, à memória coletiva e ao fluxo de saberes, que asseguram aos cidadáos o conhecimento e uso do passado, podendo intervir de maneira ativa no presente e possibilidade de previsão para elaborar melhores decisóes no futuro ${ }^{32}$, com os olhos voltados à dignidade da pessoa humana.

Por outro lado, é de se mencionar que mesmo contendo um capítulo exclusivo dedicado aos direitos sociais, a Constituição Federal não faz, ao menos não de forma contundente e específica, menção direta aos direitos culturais nesse específico ponto, limitando-se a apresentar um rol cujo enfoque recai sobre educação, saúde, trabalho, moradia, lazer, segurança, previdência social, proteçáo à maternidade e infância, e assistência aos desamparados.

Insurgências Latino-Americanas. Direito, Estado e Constituiçáa, [s.i], n. 48, p.47-75, jun. 2016, p. 48. 30 Idem.

31 QUERINO, Ana Célia; LEHFELD, Lucas de Souza. Os direitos culturais na ordem constitucional: uma análise das emendas constitucionais 42/2003, 48/2005 e 71/2012. Revista de Direito Constitucional e Internacional, [s.i], v. 90, p.201-213, jan. 2015, p. 206.

32 QUERINO, Ana Célia; LEHFELD, Lucas de Souza. Os direitos culturais na ordem constitucional: uma análise das emendas constitucionais 42/2003, 48/2005 e 71/2012. Revista de Direito Constitucional e Internacional, [s.i], v. 90, p.201-213, jan. 2015, p. 206. 
Outrossim, como anteriormente mencionado, o conjunto de normas aplicáveis à cultura no Brasil não se encontra sistematizado ou compilado em um conjunto pequeno de legislaçóes. O tratamento jurídico da cultura está disperso em diversos diplomas com pouca ou nenhuma relação entre si, a exemplo da Lei $6.533 / 78$, que regulamenta a profissão de artista e de técnico de espetáculos de diversóes, a Lei 9.610/98, que consolida a legislação sobre direitos autorais, e a Lei 8.313/91, que institui o Programa Nacional de Apoio à Cultura (PRONAC) $)^{33}$.

Em que pese a falta de coesão na proteção integral do direito a cultura, alguns entes da federação paulatinamente passaram a aprovar normas gerais que disciplinam suas respectivas políticas e sistemas regionais de cultura, situação marcante na realidade brasileira. Esse é o caso da Lei 12.365/11, que dispóe sobre a Política Estadual de Cultura e institui o Sistema Estadual de Cultura do estado da Bahia, e da Lei Complementar 934/17, que institui a Lei Orgânica da Cultura do Distrito Federal e dispóe sobre seu Sistema de Arte e Cultura. Essas legislaçóes tratam sobre princípios, objetivos, estruturas de governança e instâncias administrativas, assim como mecanismos de articulação, consulta e participação popular, instrumentos de política, sistemas de avaliação e produção de indicadores, e inclusive fontes de financiamento ${ }^{34}$.

Esta concentração na promoção do amparo às culturas regionais está diretamente insculpida na Constituiçáo Federal. O artigo 215 da Carta Maior deixa esse posicionamento evidente, na medida em que prevê que o Estado garantirá o pleno exercício das manifestaçóes culturais e, indo mais além, incentivará e apoiará a difusão dessas manifestações, dando especial ênfase na proteção das manifestaçóes de cunho popular, indígena e afro-brasileiras, como expressado no parágrafo primeiro do referido artigo.

No mesmo sentido, o artigo 216 da Constituição reconhece como patrimônios culturais brasileiros, dignos de proteção e fomento, os bens culturais materiais e imateriais, referentes à identidade, à ação, à memória dos diferentes grupos formadores da sociedade brasileira. Nesse interim, é válido frisar a proteção aos bens culturais imateriais, como as manifestaçóes, festas e práticas populares, o que, mais uma vez, demonstra a preocupação constitucional de respeitar e fomentar as culturas locais, em um país de dimensóes continentais, com práticas e costumes diferentes entre regióes e estados federativos.

No capítulo que segue, o trabalho se dedicará a analisar a Ação Direta de Inconstitucionalidade 4.983, em especial o voto dissidente do Ministro Gilmar Mendes, originária do estado do Ceará, que julgou inconstitucional a prática da vaquejada, prática considerada como parte da cultura daquele estado, sob a luz dos ditames do direito das culturas e o aparato de proteção desses direitos no sistema jurídico nacional.

33 ALEM, Nichollas. Direito da cultura, direito do entretenimento e direitos culturais: diferenças de sentido e caminhos de pesquisa. Revista dos Tribunais, [s.i], v. 998, p.453-475, dez. 218, p. 455.

34 Ibidem, p. 456. 


\section{A prática da vaquejada como direito cultural a partir do voto do ministro Gilmar Mendes no Julgamento da Açáo Direta de Incostitucionalidade 4.983}

A vaquejada é considerada prática esportiva, notadamente nos Estados do nordeste. A prática consiste na tentativa de dois vaqueiros, montados em cavalos distintos, tentarem derrubar um boi puxando-o pelo seu rabo em um determinado perímetro previamente demarcado ${ }^{35}$.

As vaquejadas simulam algumas técnicas desenvolvidas pelos vaqueiros para a lida com o gado na várzea, característica daquela regiáo do país, especialmente para recuperar aqueles animais que, por diferentes razóes, se desprendiam das fazendas onde haviam nascido e se perdiam na caatinga ${ }^{36}$. Com o passar dos anos, a referida atividade ganhou cunho folclórico, com o escopo de rememorar as raízes dos povos da regiáo.

Nesse contexto, a Ação Direta de Inconstitucionalidade 4.938 fora proposta pelo Procurador Geral da República, visando buscar a declaraçáo de inconstitucionalidade da Lei no 15.299, de 8 de janeiro de 2013, do Estado do Ceará. O referido dispositivo legal tinha como objeto a regulamentação e, principalmente, o reconhecimento da prática da vaquejada como prática desportiva e cultural do Estado do Ceará.

Mais especificamente, a Procuradoria Geral da República impugnou os artigos 1 ao $6^{\circ}$, os quais intentavam positivar a vaquejada como prática esportiva e como forma de expressáo cultural, bem como previsóes acerca de sua validade, com a seguinte redaçáo:

Art. $1^{\circ}$. Fica regulamentada a vaquejada como atividade desportiva e cultural no Estado do Ceará.

Art. $2^{\circ}$. Para efeitos desta Lei, considera-se vaquejada todo evento de natureza competitiva, no qual uma dupla de vaqueiro a cavalo persegue animal bovino, objetivando dominálo.

$\S 1^{\circ}$. Os competidores são julgados na competição pela destreza e perícia, denominados vaqueiros ou peóes de vaquejada, no dominar animal.

$\S 2^{\circ}$. A competição deve ser realizada em espaço físico apropriado, com dimensôes e formato que propiciem segurança aos vaqueiros, animais e ao público em geral.

$\S 3^{\circ}$. A pista onde ocorre a competição deve, obrigatoriamente, permanecer isolada por alambrado, não farpado, contendo placas de aviso e sinalização informando os locais apropriados para acomodação do público.

Art. $3^{\circ}$. A vaquejada poderá ser organizada nas modalidades amadora e profissional, mediante inscrição dos vaqueiros em torneio patrocinado por entidade pública ou privada.

35 GORDILHO, Heron José de Santana; FIGUEIREDO, Francisco José Garcia. A vaquejada à luz da Constituição Federal. Revista de Biodireito e Direito dos Animais, Curitiba, v. 2, n. 2, p. 78-96, dez. 2016, p. 79.

36 Ibidem, p. 81. 
Art. $4^{\circ}$. Fica obrigado aos organizadores da vaquejada adotar medidas de proteçáo à saúde e à integridade física do público, dos vaqueiros e dos animais.

$[\ldots]$

Art. $5^{\circ}$. Esta Lei entra em vigor na data de sua publicação.

Art. $6^{\circ}$. Revogam-se as disposições em contrário.

Mais especificamente, a Procuradoria Geral da República impugnou os artigos 1 ao $6^{\circ}$, os quais positivavam a vaquejada como prática esportiva e como forma de expressão cultural, bem como previsóes acerca de sua validade, com a seguinte redação.

Em síntese, a Procuradoria Geral da República suscitou um conflito entre normas constitucionais, alegando que no caso em tela estariam em contraposição as disposiçóes constantes do artigo 225 , que asseguram a proteção ao meio ambiente e aquelas constantes do artigo 215, que garantem aos cidadãos o direito às manifestaçóes culturais como como expressáo da pluralidade. A tese principal que fora adotada pelo proponente é a de que, no caso concreto, deve-se dar mais peso a disposição do artigo 225, privilegiando o entendimento de que a proteção ao meio ambiente deve prevalecer ${ }^{37}$.

Preliminarmente, é importante pontuar que a tese elaborada pela Procuradoria Geral da República fora acolhida, por maioria, pelo pleno do Supremo Tribunal Federal, reconhecendo, portanto, a inconstitucionalidade da caracterização da vaquejada como prática desportiva e cultural. Por outro lado, será objeto de análise e reflexão neste capítulo o voto dissidente proferido pelo Ministro Gilmar Mendes que, por sua vez, tem o entendimento de que o direito a cultura e o papel da vaquejada na formação da identidade do povo cearense deve se adaptar ao dever de proteção ambiental e não ser subjugado por esse.

O Ministro elucida em seu voto que, em que pese, de fato, em alguns caso a prática da vaquejada possa conter o risco de perpetrar lesão ao animal, seria desarrazoado propor como resposta a esse problema a total proibição da prática, levando em consideração o seu forte conteúdo cultural ${ }^{38}$. Nessa esteira, o desenvolvimento de ferramentas e medidas que contribuíssem para a efetivação do desiderato do legislador, como o zelo para com a proteção do meio ambiente, fauna e flora, seriam mais coerentes com os objetivos positivados e extraídos a partir da interpretação da Constituição Federal brasileira.

Em que pese não haja previsão expressa no Direito brasileiro, mas o conceito de liberdade carrega em seu bojo uma gama alargada de outros conceitos, como a ideia de desenvolvimento livre da personalidade dos indivíduos. Esta perspectiva vai ao encontro

37 BRASIL. Supremo Tribunal Federal. Ação Direta de Inconstitucionalidade no 4.983. Propositor: Procurador Geral da República. Proposto: Estado do Ceará. Relator: Ministro Marco Aurélio. Brasília, DF, 06 de outubro de 2016. Diário Oficial da Uniáo. Brasília, 2016.

38 Idem. 
dos direitos da cultura, bem como do processo de construção da identidade pessoa do cidadão, como já visto nos capítulos anteriores.

A cultura dos indivíduos, grupos, comunidades ou de sociedades representa a sua segurança afetiva, ou seja, o elo que os liga materialmente ao local geográfico onde vivem e às pessoas que o cercam. Nesse sentido, Zambam e Boff (2015, p. 76) afirmam que a identificaçáo com a sua própria cultura mantém os grupos e os indivíduos que o compóem integrados a um todo maior e organizado de acordo com padróes e objetivos que comungam entre si.

Tais manifestaçóes culturais estão diretamente conectadas com a forma pela qual os residentes do estado do Ceará se manifestam enquanto "seres" na sua sociedade local. $\mathrm{O}$ mesmo ocorre com o fato de que algumas tribos indígenas praticam festas e rituais que, em princípio e aos olhos de um observador inserido no contexto urbano, náo sejam condizentes com os parâmetros atuais do processo civilizatório ocidental, mas ainda assim são consideradas como parte integrante da identidade daqueles povos ${ }^{39} \mathrm{e}$, portanto, possuem o direito de continuar vivendo dentro de suas tradiçóes.

A linha de argumentaçáo do Ministro vai ao encontro da constataçáo exposta no primeiro capítulo de que construção de um ambiente multicultural deve ser orientada pela opção, capacidade e disposição de construir e estabelecer relaçôes dialógicas, integradas e respeitosas para com as culturas que possuem uma matriz que náo aquela mais amplamente aceita. Ao negar esta atitude dinâmica, dotada de um cunho didático e pedagógico, corre-se o risco de negar a legitimidade moral de determinada cultura considerada "fora dos padróes aceitáveis".

Por esse motivo, afirma-se que a superação de concepçôes não dialógicas é condição primeira para que se crie o ambiente necessário para a efetiva formatação e proteçấo do direito das culturas. O Ministro Gilmar Mendes, em seu voto, propóe um olhar ampliativo para o empasse da vaquejada, na medida em que abre espaço para compreender que o prática tem profundas raízes culturais no estado do Ceará, fazendo parte da construção da identidade cultural do local e, por essa razão, não deveria ser proibida, mas sim racionalizada, de modo a adequar-se as melhores práticas de proteção aos animais.

É perigoso, seguindo o raciocínio do Ministro Gilmar Mendes em seu voto, tentar frear ou proibir o acontecimento de práticas que em alguns casos remontam há tempos imemoriáveis, como é o caso da vaquejada no estado do Ceará, eis que se encontram registros bem documentados desses eventos já nos tempos do Brasil colonial. A açáo contra ou para remediar a prática da vaquejada e similares deve ser pautada pela

39 BRASIL. Supremo Tribunal Federal. Ação Direta de Inconstitucionalidade no 4.983. Propositor: Procurador Geral da República. Proposto: Estado do Ceará. Relator: Ministro Marco Aurélio. Brasília, DF, 06 de outubro de 2016. Diário Oficial da Uniáo. Brasília, 2016. 
moderação, sob pena de se estimular que esses eventos entrem para o mundo obscuro da clandestinidade ${ }^{40}$.

Denota-se, a partir da construção teórica do Ministro Gilmar Mendes, que a formação da identidade se desenvolve a partir de elementos que são fornecidos pela Antropologia, História, Geografia, assim como pelas instituiçóes, pela memória coletiva e crenças individuais, dentre alguns demais fatores ${ }^{41}$. Ao reconhecer que a vaquejada faz parte da construção da identidade cultural do povo cearense, em especial aqueles que vivem nas áreas rurais, é desarrazoado pensar que a sua prática irá cessar pelo fato de uma decisão judicial defini-la como atentatória a saúde animal. Evidencia-se, assim, que a regularização e fiscalização da vaquejada, ao invés de sua proibição, de modo a alinhála com as melhores práticas para o cuidado com o animal é a medida mais aconselhável.

O Ministro Gilmar Mendes, seguindo o seu voto, suscitou o artigo 217 da Constituição Federal, que prevê a proteção e incentivo por parte do poder estatal ao desenvolvimento do desporto de criação nacional, sejam eles formais ou informais. Para o Ministro, fica claro que a vaquejada se trata de uma dessas modalidades desportivas protegidas pelo texto do artigo 217 da Constituição, haja vista ser praticada justamente com esse fim, e ser bastante similar a outras práticas desenvolvidas em diferentes partes do Brasil relacionadas a montaria de bois e cavalos ${ }^{42}$.

Esta previsão constitucional, vale ressaltar, vai ao encontro dos movimentos constitucionais característicos da segunda metade do século XX, que levaram uma série de países a reconhecerem em suas constituiçóes a ampla proteçáo dos direitos culturais, como é o caso dos esportes característicos de determinadas comunidades. Esses movimentos de positivação mais detalhada dos direitos das culturas vieram como uma espécie de segunda fase do constitucionalismo do início do século XX, que já se ocupava dessa temática, embora de maneira mais superficial e genérica.

Levando em conta todos esses aspectos, assomado ao grande número de praticantes e pessoas envolvidas com a vaquejada, profissionalmente ou como meio de lazer, a declaração de inconstitucionalidade de sua prática se reverteria em dano demasiadamente oneroso para essa população. Além dos ônus individuais para as pessoas envolvidas com a vaquejada, todo um sistema regional de cultura, há muito já assentado, seria fatalmente atingido e colocado na marginalidade ${ }^{43}$, em verdade, o que se verificaria na realidade é a

40 Idem.

41 SPAREMBERGER, Raquel Fabiana Lopes; COLAÇO, Thais Luzia. Direito e identidade das comunidades tradicionais: Do direito do autor ao direito à cultura. Liinc em Revista, Rio de Janeiro, v. 7, n. 2, p.681-700, jul. 2011, p. 686.

42 BRASIL. Supremo Tribunal Federal. Ação Direta de Inconstitucionalidade no 4.983. Propositor: Procurador Geral da República. Proposto: Estado do Ceará. Relator: Ministro Marco Aurélio. Brasília, DF, 06 de outubro de 2016. Diário Oficial da Uniáo. Brasília, 2016.

43 Idem. 
criminalização de uma prática umbilicalmente ligada a identidade cultural de toda uma comunidade.

Finalizando o seu voto, o Ministro Gilmar Mendes aponta que, evidentemente, não há a garantia de que o animal não será eventualmente ferido, mesmo que a lesão não seja a regra na prática da vaquejada, diferentemente do que ocorre com a chamada farra do boi, onde é sabido, desde o início, que o propósito final é o abate do animal. Aos olhos do Ministro, a finalidade da vaquejada está associada a ideia de uma prática esportiva em sentido amplo e, em razão disso, defende não a declaração de inconstitucionalidade da Lei no 15.299 , de 8 de janeiro de 2013, do Estado do Ceará, mas o maior acompanhamento desses eventos por parte do poder público, para que se crie o melhor ambiente possível para a proteçáo da integridade e bem-estar do animal.

A argumentaçáo utilizada pelo Ministro em seu voto está em consonância com a afirmação de Zambam e Boff quando sustentam ser imprescindível para uma sociedade democrática a preocupação com o direito das culturas e com seus infindáveis recursos e mecanismos de participaçáo, representação, discussão e deliberação que complementam as demandas das culturas com as demais necessidades, proposiçóes e grupos que habitam a sua órbita ${ }^{44}$. Especialmente, o exercício desse direito depende diretamente do equilíbrio entre o gozo dos direitos culturais em contato com os demais direitos e obrigaçóes constitucionais igualmente relevantes, como é o caso da vaquejada em contraste com a proteção à incolumidade física do animal.

\section{Conclusáo}

Conclui-se, portanto, que a identidade cultural é um processo de construção de significado com base em um atributo cultural ou até mais em um grande conjunto de atributos culturais que passam a se relacionar entre si e, dentre estes, alguns prevalecem sobre outras fontes de significados. Esses significados, por sua vez, pautam largamente a vida dos cidadãos que compóem os diferentes grupos sociais e são parte integrante da formação psíquica e sociológica dessas pessoas.

A identidade de um povo ou de uma cultura como um todo é resultado direto de uma mistura de costumes, comportamentos, valores e dos chamados elementos socioculturais, como é o caso da religiáo e da língua local. Outrossim, o conceito de identidade nacional pode levar a erro quanto a identificação da identidade cultural de um determinado povo, pelo fato de se reconhecer que toda identidade é formada sobre a diferença, assim, na busca pela identidade cultural é essencial o respeito pelas diferenças existentes dentro de um mesmo espaço territorial.

44 ZAMBAM, Neuro José; BOFF, Salete Oro. Direitos das Culturas e Tecnologia: Um debate que integra complexidade, tradição, diferenças e mudanças. Revista Direito e Justiça: Reflexôes sociojurídicas, Santo Ângelo, v. 24, p.73-84, maio 2015, p. 76. 
Reconhecida a fundamental importância do papel da identidade cultural na sociedade, o Direito, náo podendo ser de maneira diversa, passou a se interessar a dar um olhar mais cuidadoso para essas questóes. No decorrer do século XX a doutrina constitucional iniciou um processo de positivação do direito a cultura, incialmente de maneira mais superficial e a partir da segunda metade do século de forma mais minuciosa. É dentro desse panorama que a Constituição brasileira de 1988 é formada, tendo sido reservada dentro de seu corpo um espaço para o reconhecimento dos direitos a cultura como direitos fundamentais.

As questóes envolvendo o direito das culturas não tardaram a chegar ao judiciário a partir de sua positivaçáo. Um dos mais conhecidos e divulgados casos judiciais envolvendo aspectos de direitos culturas fora o julgamento do Supremo Tribunal Federal sobre a (in) constitucionalidade da regulamentação da vaquejada no estado do Ceará. É importante frisar que o pleno do STF considerou a Lei no 15.299, de 8 de janeiro de 2013, do estado do Ceará, que intentava regulamentar a prática, inconstitucional, por acreditar que o direito à proteção do animal deve se sobrepor ao direito ao exercício de práticas culturais.

Não obstante, este estudo dedicou-se a analisar o voto dissidente do Ministro Gilmar Mendes. Por essa razão, adotou-se a hipótese de que no voto do referido Ministro a prática da vaquejada foi descrita como sendo uma prática cultural e desportiva do estado do Ceará, não podendo ser a sua regulamentaçáo considerada inconstitucional. Ao final, pode-se concluir que a hipótese de pesquisa suscitada mostrou-se verdadeira, na medida em que o Ministro Gilmar Mendes deu maior valor a proteçáo do direito cultural dos habitantes daquela regiáo, ainda que podendo colocar em risco os animais, mas indicando uma maior atençáo para as autoridades públicas incentivaram a criaçáo de um ambiente salutar aos animais para a realização do desporto.

\section{Referências}

ALEM, Nichollas. Direito da cultura, direito do entretenimento e direitos culturais: diferenças de sentido e caminhos de pesquisa. Revista dos Tribunais, [s.i], v. 998, p.453-475, dez. 218.

BRASIL. Supremo Tribunal Federal. Ação Direta de Inconstitucionalidade no 4.983. Propositor: Procurador Geral da República. Proposto: Estado do Ceará. Relator: Ministro Marco Aurélio. Brasília, DF, 06 de outubro de 2016. Diário Oficial da Uniâo. Brasília, 2016.

CASTELLS, Manuel. O poder da identidade. A era da informação: economia, sociedade e cultura. Volume II. Tradução: Klauss Brandini Gerhardt. São Paulo: Paz e Terra, 2001. 
FERNANDES, Natalia Morato. A cultura como direito: reflexóes acerca da cidadania cultural. Semina: Ciências Sociais e Humanas, [s.1.], v. 32, n. 2, p.171-182, 8 fev. 2013. Universidade Estadual de Londrina. http://dx.doi.org/10.5433/1679$0383.2011 \mathrm{v} 32 \mathrm{n} 2 \mathrm{p} 171$.

GORDILHO, Heron José de Santana; FIGUEIREDO, Francisco José Garcia. A vaquejada à luz da Constituição Federal. Revista de Biodireito e Direito dos Animais, Curitiba, v. 2, n. 2, p. 78-96, dez. 2016

\section{ORGANIZAÇÃO DAS NAÇŌES UNIDAS, ONU. Declaração Universal dos} Direitos Humanos, 1948.

QUERINO, Ana Célia; LEHFELD, Lucas de Souza. Os direitos culturais na ordem constitucional: uma análise das emendas constitucionais 42/2003, 48/2005 e 71/2012. Revista de Direito Constitucional e Internacional, [s.i], v. 90, p.201-213, jan. 2015.

RODRIGUES, Donizete. Património cultural, Memória social e Identidade: uma abordagem antropológica. Revista Ubimuseum, n.01. Universidade da Beira Interior (POR), 2012. Disponível em http://www.ubimuseum.ubi.pt/. Acesso em dezembro de 2019.

SANTOS, Boaventura de Sousa. Modernidade, identidade e a cultura de fronteira. Tempo Social. Rev. Social. USP, 5 (1-2): 31-52, 1994.

SEMPRINI, Andrea. Multiculturalismo. Tradução: Laureano Pelegrin. Bauru, SP: Edusc, 1999.

SEN, Amartya. Identidade e Violência: A ilusão do destino. São Paulo: Luminuras, 2015. Tradução de: José Antônio Arantes.

SOUZA, Pedro Bastos de. Identidade e Diversidade Cultural como Direitos Fundamentais: Relação de instrumentalidade e perspectivas no contexto internacional. Revista Videre, Dourados, v. 8, n. 15, p.147-167, jun. 2016.

SPAREMBERGER, Raquel Fabiana Lopes; COLAÇO, Thais Luzia. Direito e identidade das comunidades tradicionais: Do direito do autor ao direito à cultura. Liinc em Revista, Rio de Janeiro, v. 7, n. 2, p.681-700, jul. 2011.

WOLKMER, Antônio Carlos; FERRAZZO, Débora. Sistemas Plurais de Direito: Desde Práticas Sociais e Insurgências Latino-Americanas. Direito, Estado e Constituiçáa, [s.i], n. 48, p.47-75, jun. 2016.

ZAMBAM, Neuro José; BOFF, Salete Oro. Direitos das Culturas e Tecnologia: Um debate que integra complexidade, tradição, diferenças e mudanças. Revista Direito e Justiça: Reflexões sociojurídicas, Santo Ângelo, v. 24, p.73-84, maio 2015. 